\title{
Los emigrantes en las áreas mineras y las ciudades de Hispania: religión, identidades y difusión cultural
}

\author{
Juan Carlos Olivares Pedreño \\ Universidad de Alicante \\ jc.olivares@ua.es
}

Recibido: 3 de octubre de 2014

Aceptado: 12 de diciembre de 2014

\section{RESUMEN}

En el presente artículo analizamos los desplazamientos de cultos indígenas hispanos desde distintas áreas de la Península Ibérica hacia los principales lugares de inmigración en Hispania: las áreas mineras y las ciudades. Proponemos que estos grupos de emigrantes rendían culto en su nueva residencia a las deidades que veneraban en sus regiones de procedencia como un medio de preservar su cohesión social y su identidad cultural. La dureza de la vida laboral en las áreas mineras reforzaba la necesidad de fortalecer los lazos culturales.

Palabras clave: Religión romana. Migraciones. Identidad cultural.

\section{Emigrants to the Mining Areas and Cities of Hispania: Religion, Identities and Cultural Diffusion}

\begin{abstract}
In this paper we analyze the movements of Hispanic indigenous cults from different areas of the Iberian Peninsula to the main places of immigration in Hispania: the mining areas and cities. We propose that these groups of immigrants worshipped deities of their regions of provenance in their new residence, as a means of preserving their cultural identity and social cohesion. The hardness of working life in the mining areas reinforced the need to strengthen cultural ties.
\end{abstract}

Key words: Roman religion. Migrations. Cultural identity.

Sumario: 1. Introducción. 2. Migraciones colectivas y transmisión de cultos hacia las áreas de explotaciones mineras hispanas. 3. Migraciones colectivas hacia las áreas urbanas y difusión religiosa. 4. Migraciones individuales y testimonios privados de cultos indígenas. 


\section{Introducción}

En las últimas décadas, los movimientos migratorios y los desplazamientos de población han ido ganando un mayor espacio en la investigación sobre la Antigüedad y, en particular, sobre la época romana. ${ }^{1}$ Paralelamente al auge de estas perspectivas en los estudios antropológicos, ${ }^{2}$ se ha ido concediendo mayor importancia a conceptos como la transferencia cultural y la transformación de las identidades, así como a las consecuencias históricas que estos procesos generaban. En este sentido, son muy acertadas las palabras de Moatti: "being a structural component of human experience and the human mind, movement necessarily influences ways of thinking, relations of men to space, time, tradition, and the organization of societies..., modifies the perception of things and of human relations". ${ }^{3}$

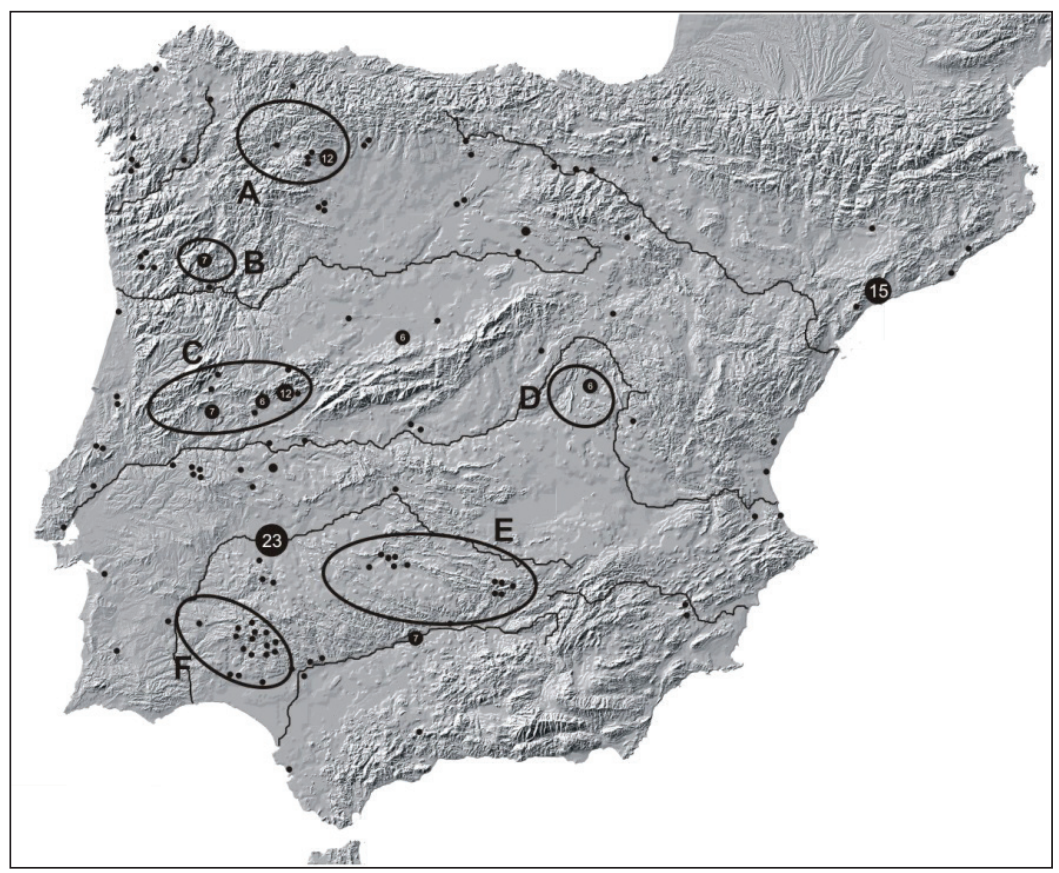

Fig. 1. Emigrantes desplazados a larga distancia $(>150 \mathrm{~km})$ en Hispania, exceptuando los obligados por cargos administrativos, según epígrafes con registro de origo, en relación con áreas mineras hispanas de época alto-imperial: A) el área astur B) región de Tres Minas C) áreas lusitanas al norte del Tajo D) área minera de lapis specularis en torno a Segobriga E)

Sierra Morena oriental F) Riotinto-Sierra Morena occidental.

1 El presente trabajo se ha realizado dentro del proyecto de investigación HAR2012-32881, Manuscritos epigráficos españoles de los siglos XVI-XIX: entre la Historiografía y la Epigrafía científica, otorgado por la Secretaría de Estado de Investigación, Desarrollo e Innovación del Gobierno de España.

2 Clifford 1997; García Canclini 1989.

3 MoAtтi 2006, 110. 
En los últimos años se ha hecho patente la importancia que estos movimientos de población tuvieron para la estructuración social de la Hispania romana así como sus consecuencias desde el punto de vista cultural y religioso. En este sentido, algunos estudios recientes relacionaban la transferencia de cultos indígenas con procesos acontecidos en determinadas áreas mineras de la Hispania romana. En estos trabajos, se establecían diversas hipótesis: que las ofrendas cultuales a deidades en una región determinada de la que no eran originarias se llevaron a cabo, prácticamente en su totalidad, si en esta región había un numeroso grupo de devotos a esa divinidad, tan cuantioso como para que esas comunidades pretendieran plasmar sus referencias identitarias lejos de su patria. ${ }^{4}$ Esto ocurrió también, por ejemplo, en los territorios mineros de Dacia ${ }^{5}$ y en menor medida, en Galia ${ }^{6}$ o Britania. ${ }^{7}$ Al deseo de los trabajadores de las minas de reforzar sus lazos culturales y sus sentimientos identitarios, se unía el hecho de que las explotaciones exponían a los mineros a grandes esfuerzos y elevados riesgos para la salud, lo que aumentaba sus sentimientos de equipo y su solidaridad colectiva, dando un cierto equilibrio a su existencia en las explotaciones mineras. Por otra parte, las condiciones laborales en las minas también excitaban los

4 Sobre los fundamentos de esta hipótesis para Hispania, vid. Olivares Pedreño 2003, 305 y 308-309. También Noy $(2000,159)$ afirmaba que la transmisión de elementos identitarios y su mantenimiento en tierras lejanas dependía del peso demográfico del grupo de emigrantes que se hubiera desplazado.

5 Dobruna-SAlihu (2007-2008, 158 ss. y 163-164, n. 14) planteaba esta difusión de elementos culturales como un intento de preservar las tradiciones nativas, como la ofrenda a la diosa Dardania en Alburnus Maior, que vinculaba a los mineros con la región de Dardania, en el Ilírico. Por otra parte, el dios Jano Geminus, muy difundido por el Nórico y oeste de Dalmacia, se difundió hasta Dacia, pero sólo se constata en las minas de Alburnus Maior (vid. Wollmann 1996, 209-210), donde se vincula al kastellum Ansis. Éste estaba habitado por gentes, precisamente, del Nórico y noroeste de Dalmacia (PundT 2012, 114-115). Wollman (1989, 112-116 y 1996, 165 ss.), Nemeti - Nemeti (2010, 111-114) y Ciugudean (2012, 104) incidían en las migraciones de grupos de mineros dálmatas e ilirios, como los citados ansi o los pirustae, baridustae, sardeates o maniates; egipcios (Wollmann, 1996, 213 ss.; CARBó 2010, 101) o de Bitinia, Galacia, Capadocia y Siria (Wollmann, 1996, 163-164 y 214 ss.; CARBó 2010, 314-315, 469, 474, 569 -que habrían difundido los cultos a Zeus Narenus o Júpiter Tavianus-), hacia las minas dácicas, aunque en estos casos hay alguna duda, como precisa DušAnić $(1989,155)$. La existencia de estos grupos indujo a la relativa conservación de sus patrones organizativos y culturales. Estos procesos de avalanchas migratorias y de creación de subgrupos étnicos fuertemente integrados, incluso con liderazgos e instituciones políticas y organizativas propias, se pueden también constatar en explotaciones mineras de épocas muy recientes, donde muchos de los individuos convivían con familiares en la explotación y donde se creaban grupos numerosos con sentimientos de identidad común (Douglass 2002, 102 y Bell 2002, 32, sobre las minas californianas y australianas; DunBAR MoodiE 1994, 29-32 y HARRIEs 1994, 5-7 y 64 ss., sobre las minas de oro sudafricanas y mozambiqueñas, durante los siglos XIX-XX; o Tandeter 1992, 42-45 y GonzÁlez Casasnovas 2000, XV, 29, 40 ss., 100-104, sobre las minas peruanas de Potosí en los siglos XVI-XVIII y el sistema de la mit'a y la relación de los emigrantes mineros con los curacas de sus territorios de origen; MARCHENA 2000, 46-49 y 61, sobre los barrios de Potosí donde residían los trabajadores, separadamente, por grupos étnicos y sus distintas festividades, cofradías y hermandades).

6 Sobre la difusión de cultos en las áreas mineras galas de Hautes-Pyrénées y su relación con comunidades concretas como la ofrenda a Ageio por los pagani Ferrarienses, vid. BEYRIE et al. 2000, 50-51.

7 Las dedicaciones a deidades, principalmente originarias del área de Tréveris (Trier, Rheinland-Pfälz), en el sudoeste de Britania se vinculan a causas económicas, entre las que estaba la riqueza minera de la región, pero destacan más otros factores, como la gran disponibilidad de tierras de cultivo (BRANIGAN 1973, 94). Sobre las explotaciones britanas del área galesa, vid. TimberLaKe 2004, 64 ss. 
temores, supersticiones y devociones religiosas de los trabajadores, lo que impulsaba la manifestación de sus creencias por medio de símbolos y rituales comunes. ${ }^{8}$

En lo que respecta a Hispania, los territorios más característicos donde se produjeron estas irrupciones de cultos de grupos de emigrantes fueron las grandes explotaciones mineras, que atraían grandes contingentes de población para trabajar, como se evidencia en la fig. 1, al igual que ocurre también en regiones mineras de todo el imperio romano. ${ }^{9}$

En estas áreas se producía un nivel muy alto de influencia cultural romana, habida cuenta de la participación de numerosos efectivos administrativos y militares en los procesos de explotación de las minas. Esto, en ocasiones, hacía que grupos de población vinculados a castella o collegia que, aunque nunca hubieran utilizado monumentos epigráficos, recintos sagrados u otros elementos para expresar sus creencias en sus lugares de origen, lo hicieran en los lugares de destino, donde la plasmación de sus señas de identidad, en coexistencia con los cultos romanos más vinculados a las actividades extractivas, se hacía más relevante como elemento de diferenciación ante el resto de la población. ${ }^{10}$

Por otra parte, en el caso de que este tipo de manifestaciones religiosas, lejos de su ámbito cultual, se dieran en áreas de escasa atracción migratoria, esos monumentos epigráficos debían, probablemente, estar ubicados en recintos privados, puesto que un monumento epigráfico o templo público dedicado a una deidad necesita una comunidad de devotos suficientemente amplia y no tendría sentido en un lugar donde la divinidad venerada no fuera ampliamente conocida. ${ }^{11}$

Otro de los ámbitos donde la afluencia de inmigrantes podía ser amplia como para justificar una difusión de cultos era la ciudad, principalmente las capitales conventuales y provinciales, aunque aquí la atracción de elementos culturales foráneos no fue tan intensa, o tan patente, como en las grandes explotaciones mineras. Por tanto, cualquier testimonio epigráfico de cultos no romanos en las ciudades debería ser interpretado teniendo en cuenta, además de que pudiera ser un culto arraigado en esa

8 Dunbar Moodie 1994, 16-21; Harries 1994, 64 ss.; Dušanić 2003, 264; Martins 2008, 113.

9 En casos en que hubieran numerosos individuos del mismo origen en las explotaciones, esto podía suponer un estímulo para que otros compatriotas siguieran el mismo camino (Noy 2000, 54-55). Sobre la transmisión de ideas y sentimientos de identidad colectiva por migraciones grupales a las minas en Dacia, vid. NEMETI Nemeti 2010, 111-114 y Pundt 2012, 18 ss. En lo que respecta a emigrantes ilirios, vid. CiobANu 1999,202 ss. y Dobruna-Salinu 2007-2008, 160-162. En este sentido, se ha de resaltar la existencia de antropónimos ilíricos entre los habitantes de las áreas mineras de Dacia, así como topónimos y etnónimos (CIOBANU, ibid., 204 ss.; Dobruna-SAlihu, ibid., 158-159 y Nemeti - Nemeti, ibid., 113-117) e, incluso, costumbres funerarias propias (Wollmann 1996, 221 ss.; NeMETI - NeMETI, ibid., 123-130). Algunos trabajadores podían ser llevados forzadamente a las áreas mineras (Flor., 2, 25, 12), como los peregrini llevados de Dalmacia a Mesia Superior y Dacia (DušANić 1977, 74, n. 137 y 93, n. 264; ID. 1989, 148 ss. y 155), pero una mayoría de los mineros acudían libremente a trabajar, al menos en época imperial, como también se testimonia en Panonia, Dalmacia, Mesia y Dacia (Davies 1935, 14-15; Healy 1978, 135 ss.; Andreau 1990, 90-91; Pund, ibid., 35-38 y 75-78), Galia (Beyrie et al. 2000, 52) o Hispania (SANtos YanguAs 1997, 222-229).

10 Pundt 2012, 58-59. La influencia romana también motivaba la integración de las poblaciones mineras indígenas en los cultos y la cultura romana, con los consecuentes procesos de hibridación (DuŠANIĆ 1977,57 ss.; Wollmann 1996, 119 ss.; Ciobanu 1999, 202 ss.; Beyrie et al. 2000, 52 ss.; Pundt, ibid., 82-87 y 116-117; Nemeti - Nemeti 2010, 121-122).

11 Olivares Pedreño 2013, passim. 
ciudad, la posibilidad de que pudiera tratarse de una difusión derivada de procesos migratorios.

Para defender estas hipótesis, nos proponemos calibrar todos los casos conocidos en Hispania de transferencias de cultos, para establecer un balance general del proceso de difusión religiosa en relación con los movimientos migratorios masivos y, por otra parte, de las manifestaciones privadas de cultos hechas por individuos o familias emigrantes.

En cualquier caso, hemos de tener presente que todos los intentos, por parte de estos grupos de emigrantes, de fijar y mantener las tradiciones propias, estaban inmersos en un proceso más profundo de transformación política, económica, social y cultural, que llevaba progresivamente a la adopción de los modos de vida, costumbres, ideas, creencias, símbolos y manifestaciones rituales del Estado romano. ${ }^{12}$

\section{Migraciones colectivas y transmisión de cultos hacia las áreas de explotaciones mineras hispanas}

No es siempre posible establecer cuándo un culto es propio de un área determinada puesto que, en ocasiones, no es conocido el conjunto de divinidades autóctonas de todas las regiones y, en consecuencia, la aparición en un zona minera del testimonio de una determinada divinidad es, a menudo, un caso único y no es posible adscribirla a un ámbito cultural concreto. ${ }^{13}$

La idea que planteamos se puede observar con bastante claridad cuando analizamos los testimonios del culto al dios Coso o Cossue en la Península Ibérica (fig. 5), que se extienden por la región costera del Océano Atlántico desde el centro de Portugal hasta el Cantábrico. Estos testimonios no aparecen en toda la región interior de Portugal y Galicia pero, en cambio, vuelven a encontrarse algunas aras de la deidad más al este, desligadas del resto, en el entorno de las explotaciones auríferas romanas de El Bierzo (León). ${ }^{14}$ Ello indicaría una migración desde la costa noroccidental de Hispania hacia las minas de oro astures de grupos de población, parte de los cuales habrían permanecido en la región astur hasta su muerte, como muestran las estelas funerarias de emigrantes célticos supertamarcos halladas en Asturica Augusta ${ }^{15}$ y que, en consecuencia, habrían generado una difusión de elementos culturales desde la costa de Gallaecia hacia el conventus Asturum. La plasmación de esta transfe-

12 Sobre estos procesos de transformación cultural y la relación entre las identidades y las fronteras culturales, vid. Strobel 2009, 118 ss. y 138 (en relación los gálatas de Anatolia). Sobre la relación de la religión, la cultura y la etnicidad, JENKIns 2008, 17 ss. y FAWCETT 2000, 5 ss. Es probable que, como ha mostrado DuNBAR Moodie sobre algunas minas sudafricanas en la actualidad, los trabajadores fueran sometidos por los gestores de las explotaciones a procesos que directamente transgredían y alteraban drásticamente sus patrones culturales, en aras de una socialización y adaptación al nuevo contexto socio-económico de explotación (1994, 12 ss.).

13 Este problema también es patente en la información epigráfica de las regiones mineras de Dacia (Ciobanu 1999, 211 ss.).

14 Olivares Pedreño 2007, 149 ss.

15 Ibid. 148, fig. 2. 
rencia religiosa la podemos ver con claridad si cartografiamos la procedencia de los testimonios epigráficos de Coso/Cossue (fig. 5) y observamos la tabla que recoge las lápidas de inmigrantes halladas en Asturica Augusta y su entorno (fig. 2). ${ }^{16}$ Esta tabla nos muestra que los emigrantes que se desplazaron hacia el área de las minas astures procedían, principalmente, de la costa galaica y del área celtibérica. ${ }^{17}$

Podemos detectar un caso muy semejante si analizamos la ubicación de las ofrendas votivas a la diosa Ilurbeda, cuyo ámbito cultual se situaba en territorio de los vetones pero, sin embargo, dos inscripciones se hallaron cerca de la costa central de Portugal, en las minas de oro de la Serra de Lousã (Álvares, Góis, Coimbra) y, por tanto, lejos del territorio vetón. En este caso, las aras fueron halladas junto al pozo de una mina y junto a instrumentos de minero. ${ }^{18}$

\begin{tabular}{|c|c|c|c|}
\hline ORIGO & NOMBRE & PROCEDENCIA & REFERENCIAS \\
\hline Bracaraugustanus & & LEÓN, Astorga & HALEY 418 \\
\hline Bracaraugustanus & & LEÓN, Astorga & HALEY 417; CIL II 2639 y p. 707 \\
\hline Caesaraugustanus & & LEÓN, Astorga & HALEY 425; CIL II 2638 \\
\hline Castulonensis & $\begin{array}{l}\text { M. Valerius } \\
\text { Licinianus }\end{array}$ & LEÓN, Astorga & HALEY 423; CIL II 2641 \\
\hline $\begin{array}{l}\text { Celticus } \\
\text { Supertamaricus }\end{array}$ & & LEÓN, Astorga & HALEY 409 \\
\hline $\begin{array}{l}\text { Celticus } \\
\text { Supertamaricus }\end{array}$ & & LEÓN, Astorga & $\begin{array}{l}\text { HALEY 408; CIL II 2904-5081; } \\
\text { HEp 11, 2001, } 281\end{array}$ \\
\hline $\begin{array}{l}\text { Celticus } \\
\text { Supertamaricus }\end{array}$ & Claicinus Clari filius & LEÓN, Astorga & HALEY 406; $A E$ 1976, 286 \\
\hline $\begin{array}{l}\text { Celticus } \\
\text { Supertamaricus }\end{array}$ & Fusca Coedi filia & LEÓN, Astorga & $\begin{array}{l}\text { HALEY 407; CIL II 2902; CIL II } \\
5667\end{array}$ \\
\hline $\begin{array}{l}\text { Celticus } \\
\text { Supertamaricus }\end{array}$ & Eburia Calveni filia & $\begin{array}{l}\text { LEÓN, Santa } \\
\text { Colomba de } \\
\text { Somoza, Andiñuela }\end{array}$ & HEp 7, 1997, 388; AE 1997, 873 \\
\hline Cilena & Ammia Prisca & LEÓN, Astorga & $\begin{array}{l}\text { HALEY 422; CIL II 2649; CIL II } \\
5686\end{array}$ \\
\hline Cilenus & Albinus Alburi filius & \begin{tabular}{|l|} 
LEÓN, Santa \\
Colomba de Somoza
\end{tabular} & HALEY 428; EE 8, 132 \\
\hline Cluniensis & & LEÓN, Astorga & HALEY 427 \\
\hline Cluniensis & $\begin{array}{l}\text { Paternus Turenni } \\
\text { filius }\end{array}$ & \begin{tabular}{|l|} 
LEÓN, Santa \\
Colomba de Somoza
\end{tabular} & HALEY 429; HEp 1, 1989, 404 \\
\hline Uxama Ibarcensis & $\begin{array}{l}\text { Baebius Latro Nigri } \\
\text { filius }\end{array}$ & LEÓN, Astorga & $\begin{array}{l}\text { HALEY 421; } E E \text { 9, 292e; } A E \text { 1903, } \\
234\end{array}$ \\
\hline Uxamensis & Proculus Luci filius & LEÓN, Astorga & CIL II 5077; HALEY 420 \\
\hline
\end{tabular}

16 Hemos de tener en cuenta, no obstante, que lo habitual era que, una vez desarrollado su trabajo, los emigrantes volvieran a sus tierras (Noy 2000, 53), por lo que las estelas que citamos sólo son un reflejo imposible de cuantificar de lo que debió ser este fenómeno migratorio.

$17 \mathrm{Vid}$. toda la discusión sobre estas estelas en Olivares Pedreño 2007, passim. En el mismo sentido, HirT $2010,273$.

18 Olivares Pedreño 2000-2001, 249 ss.; ID. 2001, 64-65; ID. 2007, 149-150. 


\begin{tabular}{|l|l|l|l|}
\hline Uxamensis & $\begin{array}{l}\text { Caecilia Materna, } \\
\text { Titi uxor }\end{array}$ & LEÓN, León & HALEY 431 \\
\hline $\begin{array}{l}\text { Uxamensis } \\
\text { (Argaeli })\end{array}$ & Flavia Flavi filia & $\begin{array}{l}\text { LEÓN, Cacabelos } \\
\text { del Bierzo }\end{array}$ & $\begin{array}{l}\text { HALEY 402; CIL II 5672; HEp 10, } \\
\text { 2000, 350 }\end{array}$ \\
\hline Uxamensis & & LEÓN, León & HALEY 432; CIL II 5685 \\
\hline
\end{tabular}

Fig. 2. Estelas funerarias de emigrantes hacia el área de las minas astures.

No son los únicos casos de transferencia cultual hacia las áreas mineras. Las $M a$ tres aparecen testimoniadas también en áreas lejanas de su ámbito cultual nuclear en Hispania, que sería el territorio celtibérico, según se evidencia por la práctica totalidad de ofrendas votivas halladas en la región oriental de la Meseta Norte (fig. 3). En este sentido, un ara dedicada a las Matres se halló también en las regiones mineras de El Bierzo, en San Esteban del Toral (Bembibre, León), ${ }^{19}$ testimoniando una migración de celtíberos hacia las minas de oro, algo que corroboran, como ya vimos, varias estelas funerarias de uxamenses halladas en los alrededores de la capital astur (fig. 2). ${ }^{20}$

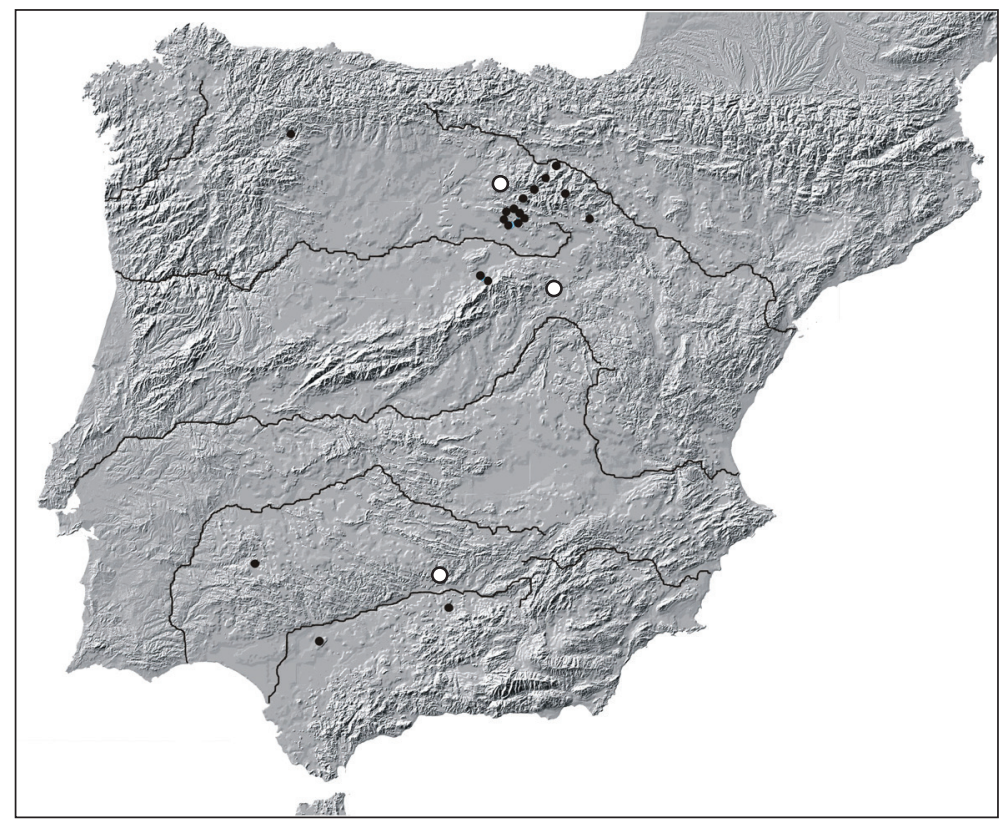

Fig. 3. Testimonios epigráficos de las Matres (círculos negros) y de Epona (círculos blancos) en Hispania.

19 Rabanal - García Martínez 2001, no 23; Olivares Pedreño 2007, 150.

20 García Merino $(1975,191)$ concluía que la verdadera migración de gentes desde el conventus Cluniensis se produjo, básicamente, por motivos laborales y socio-económicos hacia el noroeste peninsular, el suroeste de la Meseta y las minas de Sierra Morena; Olivares Pedreño 2007, 148, fig. 2. 
Además, tenemos el testimonio de Cacabelos del Bierzo, dedicado por Flavia, a una diosa llamada Degantia o Deganta in honorem argael[...], que diversos autores interpretaron como una ofrenda en honor de los argaeli de la ciudad celtibérica Uxama Argaela. Nosotros mismos consideramos que esta pieza podría indicar la difusión del culto de una deidad celtibérica hacia las minas bercianas, lo que quedaría apoyado por las citadas estelas funerarias alusivas a uxamenses en esa región, siendo una muestra de los sentimientos de identidad común que se podían crear y reforzar en los territorios mineros por poblaciones emigrantes. ${ }^{21}$ Recientemente, se ha formulado la hipótesis según la cual el término argael... podría hacer referencia al nombre de un populus/civitas o de una cognatio o grupo de parentesco del territorio astur, ya que no es habitual que el término in honorem se utilice para aludir a los habitantes de una ciudad. ${ }^{22}$ Esto también es posible pero, dado que el único topónimo que conocemos en la actualidad al que se pueda referir la inscripción es Uxama Argaela, que habitantes de esta ciudad habían emigrado a las regiones mineras astures a tenor de las inscripciones registradas y que, además, en las áreas mineras se daban habitualmente concentraciones de emigrantes procedentes de un mismo lugar que mostraban sus devociones en inscripciones, no podemos descartar que el texto se refiera a emigrantes de Uxama. Ello sería un ejemplo de mención de un colectivo inmigrante en la región minera, equivalente a los casos de dálmatas e ilirios que citaban sus comunidades de origen en las minas dácicas donde, incluso, realizaron una ofrenda con la misma fórmula in honorem. ${ }^{23}$ Con todo, como afirman González Rodríguez y Ramírez, ${ }^{24}$ la hipótesis no se puede dar por segura y que la pieza se pudiera referir a una comunidad astur es también plausible.

Desde la región celtibérica se difundieron también cultos hacia otras áreas de la Península Ibérica, como atestigua la ofrenda dedicada a Epona hallada en Andújar (Jaén). ${ }^{25}$ La diosa Epona está testimoniada en toda la Europa céltica con cientos de testimonios escultóricos y epigráficos, en las fuentes literarias ${ }^{26} \mathrm{y}$, en Hispania, principalmente en epígrafes hallados en el área celtibérica, en Lara de los Infantes (Burgos), Sigüenza (Guadalajara) y, quizás, en Monte Bernorio (Palencia), aunque esta última es de muy reducidas dimensiones, por lo que podría haber sido llevada allí

21 Blázquez 1962, 77; Mañanes 1981, 169; Tranoy 1981, 298; Diego 1986, 74-75, nº 59; Haley 1986 , 394-395; Olivares Pedreño 2002, 177; ID. 2007, 150. Sobre los collegia o castella formados por emigrantes de comunidades organizadas con sus propias instituciones en Riotinto, como se ve en la ofrenda del collegium salutare a Júpiter (BlázQuEz 1986, 428) y también las minas de Alburnus Maior (Dacia), como el kastellum Ansis, el collegium kastelli Baridustarum, el collegium Galatorum o el collegium Sardiatarum, que hacían ofrendas a sus dioses y genios, vid. Wollmann 1989, 112-113; ID. 1996, 209 ss.; NEMETi 2004, 92; DobrunASALIHU 2007-2008, 162-163 y PundT 2012, 118-120.

22 GonzÁlez Rodríguez - RAmírez $(2010,72)$ exponen el único paralelo hispano: un templo dedicado a las Ninfas in honorem Edetanorum (CIL II 3786; CoReLl 2008, 42-44, $\mathrm{n}^{\circ}$ 1).

23 Vid. supra. sobre los emigrantes ilirios y dálmatas en Alburnus Maior. La referencia a que aludimos es la ofrenda dedicada a [Nymphis et Sil]vano / [Augusto in] honor(em) / [col(legii) M(anliensium)] (HAINZMANN - SCHUBert 1986, nº 112).

24 GonzÁlez Rodríguez - RAMíRez 2010, passim.

25 Corell - Gómez Font 2002-2003, 239-242; HEp 12, 2002, 299; AE 2002, 726.

26 EUSKIRCHEN 1993, 740 ss. 
desde otro lugar y también el enclave de su hallazgo es discutido, puesto que apareció en una colección privada. ${ }^{27}$

Por tanto, cabe pensar que los recursos minero-metalúrgicos permiten una explicación coherente al culto de Epona en el área oriental de Sierra Morena. ${ }^{28}$ Todo el norte de la actual provincia de Jaén fue en época romana un territorio ocupado por minas, en el entorno de Los Villares, donde se ubicaba Isturgi y donde, además, se hallaban las minas de Arroyo Valquemado, Cerro de los Venados, Arroyo de la Lisea, El Fresnillo, El Humilladero, Navalasno y Los Escoriales. ${ }^{29}$ A esta región llegaron gentes desde lugares lejanos, incluso desde más allá de los Pirineos, si tenemos en cuenta la mención de Plinio sobre la presencia de aquitanos en la zona. ${ }^{30} \mathrm{La}$ difusión de cultos desde la región celtibérica hacia Sierra Morena oriental está también corroborada por el registro de estelas funerarias de emigrantes en el área norteña de Jaén puesto que, si tenemos en cuenta los inmigrantes de larga distancia que llegaron a la zona, considerando éstos como los que se desplazaron más de $150 \mathrm{~km}$ en línea recta hasta su destino (fig. 4), el 60\% lo hicieron desde territorio celtibérico. ${ }^{31}$ Algunos de estos pobladores acabaron su vida en la capital económica de la región, Castulo, al igual que los emigrantes que se dirigieron hacia las áreas mineras del noroeste, que murieron en su capital, Asturica Augusta. ${ }^{32}$ Castulo fue el núcleo desde el que se centralizaban y comercializaban los metales obtenidos en todo el distrito minero de Linares-La Carolina-Andújar y donde se ubicarían los talleres de forja y los alfares ya desde época protohistórica, incrementándose su importancia en los períodos ibérico y púnico y llegando hasta época romana, cuando la explotación de cobre y galena argentífera alcanzó niveles máximos nunca igualados hasta la época industrial. ${ }^{33}$

\begin{tabular}{|l|l|l|l|}
\hline \multicolumn{1}{|c|}{ ORIGO } & \multicolumn{1}{|c|}{ NOMBRE } & \multicolumn{1}{c|}{ PROCEDENCIA } & \multicolumn{1}{c|}{ REFERENCIAS } \\
\hline Orgenomescus & Paternus, Cant... & JAÉN, El Centenillo & HALEY 521; HAE 1831 \\
\hline Cluniensis & $\begin{array}{l}\text { Pompeius Fraternus, } \\
\text { Gai filius }\end{array}$ & $\begin{array}{l}\text { JAÉN, La Carolina, cerca de } \\
\text { las minas de El Centenillo }\end{array}$ & $\begin{array}{l}\text { HALEY 520; AE 1922, 8; } \\
\text { AE 1922, 8 }\end{array}$ \\
\hline Segobrigensis & L. Annius Capella & JAÉN, Linares, Castulo & HALEY 524 \\
\hline Segisamensis & L. Caelius Flavinus & JAÉN, Linares, Castulo & HALEY 523; CIL II 3281 \\
\hline Laxcutensis & M. Magius & JAÉN, Vilches & HALEY 518; AE 1913, 10 \\
\hline
\end{tabular}

Fig. 4. Estelas funerarias de emigrantes de larga distancia en el área minera de Sierra Morena oriental.

Podemos afirmar que otras deidades también se difundieron desde su territorio original, a pesar de que sólo se han testimoniado epigráficamente una vez. En el área del

27 Olivares Pedreño 2002, 120-121 y 251-254, con bibliografía.

28 Sobre el área minera de Sierra Morena oriental, vid. ConTreras Cortés - Dueñas Molina 2010, passim.

29 Blázquez 1986, 315-319 y 367-368; Domergue 1987, I, 254-261.

30 Plin., N.H., 33, 97. AndREAu 1990, 90, reafirmando la fiabilidad del término aquitani.

31 La mayoría habrían venido desde el conventus Cluniensis (GARCía Merino 1975, 187-189 y 191), mientras que la llegada desde el Caesaraugustanus sería irrelevante (MAGAlLón - NAVARro 1991, passim).

32 Ya citamos arriba (Noy 2000,53) que esto no era la norma.

33 Arboledas 2010, 132-136, con fig. 171. 
foro de Arucci (Aroche, Huelva), que era una ciudad situada en el núcleo de región minera de la Bética occidental, se halló una placa de bronce que contenía una ofrenda de una mujer llamada Iunia Avita a unas deidades denominadas Rixamis (dat.). Apareció en la curia de la ciudad, en un nivel del s. III d.C. que reaprovechaba la estancia con usos distintos al original. ${ }^{34}$ Desde el punto de vista lingüístico, el nombre era céltico, lo que se veía apoyado por el insólito hecho de que aparecía citado por Marcial en uno de sus epigramas en el que, entre otros lugares y tradiciones celtibéricas, mencionaba a "Tudela, los coros de las Rixamas, los festivos banquetes de Garduas...". 35 Por tanto, a partir de la pieza hallada en Aroche, se puede concluir que el término Rixamae de Marcial no era un topónimo ni un etnónimo, sino que correspondía a deidades indígenas del panteón celtibérico, de una tipología semejante a las Matres o las Ninfas. ${ }^{36}$ En definitiva, tenemos en Aroche una ofrenda a divinidades celtibéricas realizadas por emigrantes que se dirigieron a la región minera del occidente bético.

El descubrimiento de la dedicación a las Rixamae celtibéricas se enmarca, de nuevo, en la transmisión de cultos hacia regiones de fuerte atracción migratoria, como las ricas explotaciones mineras del área de Riotinto y, en general, de las áreas montañosas de la Beturia céltica. ${ }^{37}$ Las migraciones hacia esta región tenían su origen, principalmente, en el área galaica y lusitana, aunque también se testimonian llegadas de población desde Celtiberia. ${ }^{38}$ En Riotinto, estas poblaciones crearon collegia con diversos fines, como el collegium salutare testimoniado en la zona que hace una ofrenda a Júpiter Óptimo Máximo y que tiene paralelos, como hemos visto, en las explotaciones mineras dácicas, contribuyendo a reforzar los lazos comunitarios e identarios entre los trabajadores de las minas. ${ }^{39}$

Otros testimonios hallados en la zona también podrían corresponder a cultos paleohispánicos, como los bloques procedentes de la ladera del Cerro Salomón, situado sobre la Cueva del Lago, donde se habría ubicado un poblado de trabajadores de las minas. Según algunos autores, estos bloques guardan un cierto paralelismo con un relieve de Lourizán (Pontevedra) que representaría a una deidad galaica llamada Vestius Aloniecus, puesto que dicho relieve se halló junto a dos aras dedicadas a este dios..$^{40}$ A pesar de las dificultades para interpretar con precisión estos materiales, Blanco planteaba dudas sobre su carácter, teniendo en cuenta que se hallaron disper-

34 La pieza tenía pestañas que, probablemente, servían para fijarla a un ara (BERMEJo MELÉNDEZ 2011, 68). La lectura correcta la llevaron a cabo GIMENO - ROTHENHÖFER 2012, 436.

35 Mart., Epig., 4, 55, 16-17: Tutelamque chorosque Rixamarum, et convivia festa Carduarum (trad. de J. Fernández Valverde y A. Ramírez de Verger, Marcial. Epigramas I, Gredos, Madrid, 1997, 286). Sobre el análisis del nombre y su interpretación, GIMENO - RoTHENHÖFER 2012, 436-438. No obstante, la identificación de Tutela con Tudela, tal como se ofrece en la traducción que citamos es cuestionable (Ibid. 437, n. 3).

36 GIMENO - RothENHÖFER 2012, 437.

37 Str., III, 2, 8. Sobre la gran riqueza minera de la región, sobre todo plata, vid. PÉrEz MACÍAs et al. 1997, 200; BeRMEJO 2011, 25, 129-130, 147-148.

38 ORIA 1997, 206-209. Del área celtibérica conocemos una mujer, Licinia Materna, llegada de Novaugusta hacia las minas de río Tinto (HALEy 1986, nº 194; AE 1965, 300; HAE 2172; GonZÁLEZ, 1989, nº 39); un hombre termestino, Iulius Campanus, en una estela de Almonaster la Real, Huelva (HaLEY 1986, n 196; GoNZÁleZ, 1989, nº 47).

39 Blanco Freijeiro 1962, 44-45; Oria, 1997, 211-212.

40 Blanco Freijeiro 1962, 41; Oria, 1997, 206-207. 
sos con otros sillares que habían sido reutilizados en muros de época almohade, pero les adjudica, a partir de criterios formales, una vinculación con los relieves célticos hispanos y transpirenaicos. ${ }^{41}$ Esto, por otra parte, sería posible dada la esencia de los territorios mineros como ámbitos de confluencia cultural en Hispania, aunque no podemos precisar más por el momento.

Otro ejemplo de este tipo de difusión cultual viene dado por el descubrimiento reciente de una inscripción dedicada a un dios denominado Salaecus, que apareció en la sierra minera de Cartagena, aunque la cronología de esta ofrenda es de finales del s. II a.C. ${ }^{42}$ No tenemos testimonios epigráficos de inmigrantes en este ámbito minero, aunque sí las informaciones de Estrabón, que afirma que las minas daban trabajo 40.000 individuos de modo permanente y que reportaban al Estado romano 25.000 dracmas diarias. ${ }^{43}$ Esta carencia de información epigráfica de inmigrantes, paradójica a primera vista, es plenamente coherente puesto que cuando se comenzó a extender el hábito epigráfico en la Península Ibérica, ya durante el Alto Imperio, las minas de Carthago Nova estaban en decadencia y no eran tan productivas como en época republicana. ${ }^{44}$ Por ello la ofrenda votiva a Salaecus es también de esta época, realizada cuando las minas del sureste hispano estaban en su máximo rendimiento.

Cuando publicamos la ofrenda a Salaecus, la interpretamos, de modo preferente, como un apelativo de Neptuno a partir de varios hechos: en primer lugar, por la paredría del dios romano con la deidad femenina Salacia y por la vinculación fonética del nombre Salaecus y de la diosa con el mar; en segundo lugar, por los fluidos contactos económicos y demográficos de Carthago Nova con la Península Itálica y, finalmente, por la afluencia a la región de otros cultos itálicos y orientales durante fines del período republicano. ${ }^{45}$ Además, sabemos que Neptuno era una divinidad muy venerada en ámbitos mineros, quizá por el uso masivo del agua que había en las minas. ${ }^{46} \mathrm{Sin}$ embargo, también tuvimos en cuenta la posibilidad de que se tratara de la ofrenda a una deidad paleohispánica a partir de la llegada de esclavos hispanos hacia las minas del sureste después de las guerras lusitanas y celtibéricas. ${ }^{47}$ Conscientes de la dificultad de tomar una posición cerrada, esta última hipótesis va cobrando algo más de más peso a medida que aparecen nuevos testimonios epigráficos de divinidades célticas hispanas en áreas mineras.

Otro posible ejemplo de difusión cultual hacia regiones mineras es el que nos muestra el ara dedicada, probablemente, a Vacus, por una mujer llamada Acara, sier-

41 Blanco FreiJeiro 1962, 39-41.

42 González Fernández - Olivares Pedreño, 2010, 109-126.

43 Str., III, 10.

44 González Fernández - Olivares Pedreño, 2010, 117.

45 Ibid. $119-122$.

46 Nemeti 2004, 93-94 y Pundt 2012, 112-113, n. 391, resaltan que en las minas Alburnus Maior, la interpretatio de Neptuno hecha por mineros del Illyricum, era una de las más adoradas, más aún que en las cercanas ciudades de Apulum o Ampelum, lo que indicaría su relación directa con la explotación del mineral, con los problemas que acarreaba ésta, como las inundaciones subterráneas o los movimientos de tierras y con los movimientos sísmicos. La mayoría de los dioses del área eran romanos, pero con apelativos originarios de la región de procedencia de los inmigrantes (NEMETI 2004, 98).

47 Ibid., 123. 
va de Maternus y que fue hallada en Corral de Calatrava (Ciudad Real). ${ }^{48}$ El ara no se halló en su ubicación original, pero la comarca de Corral de Calatrava está en el entorno inmediato de numerosas minas antiguas en los términos de Abenójar, Almodóvar del Campo, Brazatortas, Cabezarados, Cabezarrubias del Puerto, Calzada de Calatrava, Mestanza, San Lorenzo de Calatrava y Villamayor de Calatrava. ${ }^{49}$ El teónimo Vacus está testimoniado en Astorga y La Milla del Río (León) (fig. 5) donde, además, existía un santuario dedicado al dios. ${ }^{50}$ Por otra parte, el nombre de la dedicante a Vacus en Corral de Calatrava, Acara, está testimoniado en masculino con una variante fonética, como Acarius, exclusivamente en el área leonesa, en Barrillos de Curueño y Valencia de Don Juan (León) ${ }^{51}$ lo que es un apoyo más a la hipótesis de una difusión del culto a la deidad desde la Meseta Norte hacia la región minera situada al sur del Guadiana aunque, como es lógico, los datos son demasiado escasos para que podamos considerar esta hipótesis como del todo fiable.

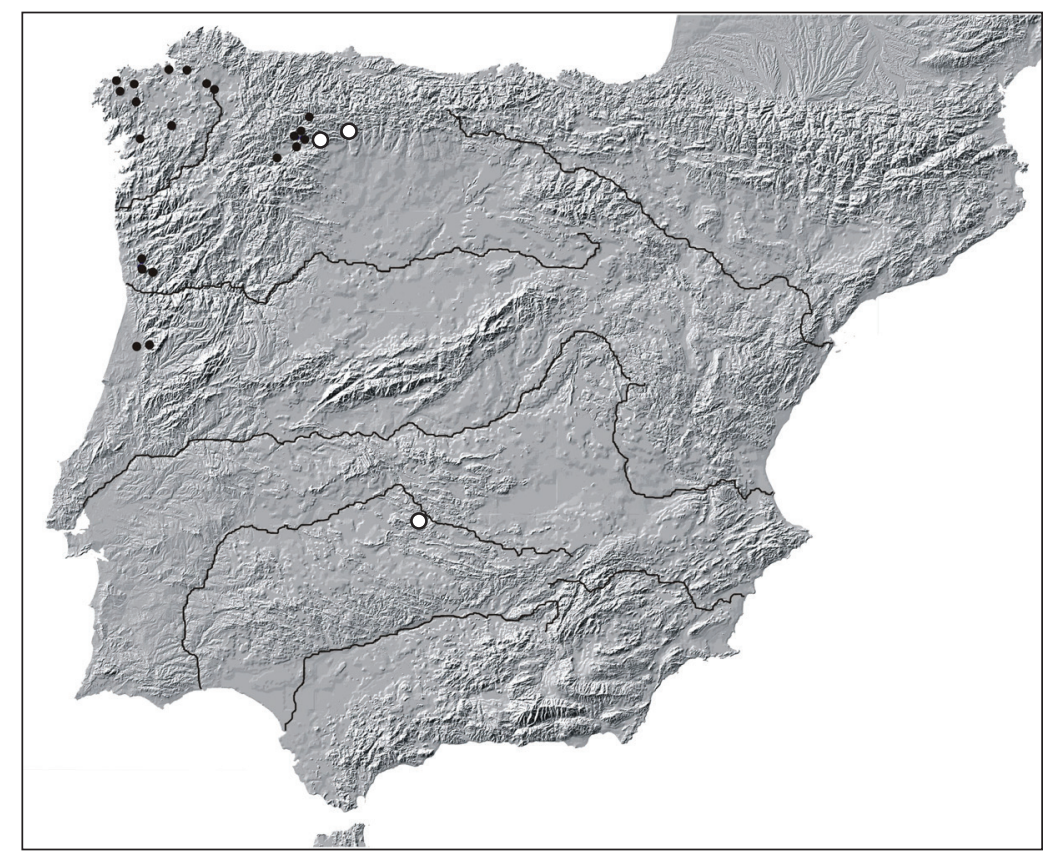

Fig. 5. Testimonios epigráficos de Cosus (círculos negros) y Vacus (círculos blancos) en la Península Ibérica.

48 AlföLdy $\left(1987,237-239, n^{\circ} 7\right)$ mostraba dudas sobre la primera letra del nombre de la deidad, puesto que el espacio estaba dañado: proponía Aco o [-]aco. En el último caso, sugería la lectura [V]aco. También en HEp 2, 1990, 285; Olivares Pedreño 2002, 44.

49 Domergue $(1987,59-85)$ cita todo un cúmulo de explotaciones en este área: CR 1, 2 y 3 (Abenójar), CR9, 10, 11, 12, 13, 14, 15, 16, 17, 18, 19 y 20 (Almodóvar del Campo), CR 22, 23, 24 y 25 (Brazatortas), CR 26 (Cabezarados), CR 27 y 28 (Cabezarrubias del Puerto), CR 29 (Calzada de Calatrava), CR 35, 36 y 37 (Mestanza), CR 38, 39, 40, 41 y 42 (San Lorenzo de Calatrava) y CR 43 (Villamayor de Calatrava).

50 Olivares Pedreño 2002, 102, con bibliografía.

51 Abascal 1994, 256. 
Otra inscripción que muestra un desplazamiento del culto hacia regiones mineras es la ofrenda a Serapis, Isis, Coré, Apolo Grannus y Marte Sagatus efectuada por Iulius Melanio, procurator Augustorum duorum, que se halló en Astorga. Apolo Grannus es una deidad muy venerada en Europa central, por lo que cabe pensar que lo era en la tierra de procedencia de Iulius Melanio o en lugares donde éste ocupó cargos. Esta pieza se ubicó en un pequeño templo en el que erigían ofrendas votivas los procuradores de las minas astures y en el que el propio Melanio instaló otros dos altares. Por tanto, debemos pensar que son testimonios de una religiosidad en el lugar de residencia oficial de los procuradores de Asturica Augusta ${ }^{52}$ por lo que no tendrían el mismo significado que los testimonios de migraciones colectivas que estamos tratando.

Otro altar votivo que se sitúa fuera del territorio en el que debiera encontrarse es el dedicado a Bandu Vordeaeco en Seixo de Ansiães (Bragança), puesto que los testimonios de ese apelativo del dios Bandua se concentran mucho más al sur. El hallado en Seixo es el más septentrional de los registrados hasta el momento, como se puede ver en las figs. 6 y 7. Este desplazamiento se justifica por la existencia de las minas de Covas de Seixo de Ansiães y de Selores en Carrazeda de Ansiães (Bragança). ${ }^{53}$

\begin{tabular}{|c|c|c|c|}
\hline TEÓNIMO & EPÍTETO & PROCEDENCIA & REFERENCIAS \\
\hline Ban[di] & Vor[tia]ecio & Malpartida de Plasencia (Cáceres, España) & $\begin{array}{l}\text { CIL II 855; AE 1999, } \\
882 ; H E p 4,1994,238\end{array}$ \\
\hline \multirow[t]{4}{*}{ Bandi } & Vordeaicui & Meda (Guarda, Portugal) & $\begin{array}{l}\text { AE 2003, 865; HEp 13, } \\
2003-2004,990\end{array}$ \\
\hline & Vortiacio & Montehermoso (Cáceres, España) & HEp 4, 1994, 242 \\
\hline & Vorteaecio? & Penamacor (Castelo Branco, Portugal) & HEp 5, 1995, 994 \\
\hline & Vortiaecii & Penamacor (Castelo Branco, Portugal) & $\begin{array}{l}A E \text { 1985, 531; HEp 3, } \\
1993,473\end{array}$ \\
\hline [Bandi]? & Vor[te]aecio & S. Martinho (Castelo Branco, Portugal) & $A E 1977,380$ \\
\hline$B($ andi)? & V(orteaeceo $) ?$ & $\begin{array}{l}\text { S. Vicente da Beira (Castelo Branco, } \\
\text { Portugal) }\end{array}$ & HEp 3, 1993, 469 \\
\hline Bandi & Vorteaeceo & $\begin{array}{l}\text { Salgueiro, Fundão (Castelo Branco, } \\
\text { Portugal) }\end{array}$ & $\begin{array}{l}A E \text { 1967, 136; AE 1977, } \\
379\end{array}$ \\
\hline \multirow[t]{3}{*}{ Bandu } & Vordeaeco & $\begin{array}{l}\text { Seixo de Ansiães, Carrazeda de Ansiães } \\
\text { (Bragança, Portugal) }\end{array}$ & $\begin{array}{l}A E \text { 1991, 1039; AE 1992, } \\
994 ; \text { HEp 5, 1995, } 986\end{array}$ \\
\hline & \begin{tabular}{|l|} 
Vord $[i]$ o \\
Talaconio
\end{tabular} & Sortelha, Sabugal (Guarda, Portugal) & $\begin{array}{l}A E \text { 1999, 868; HEp 9, } \\
1999,746\end{array}$ \\
\hline & Vordiaecio & Zarza de Granadilla (Cáceres, España) & HEp $11,2001,141$ \\
\hline Bandi & Vordiaigevi & $\begin{array}{l}\text { Aldeia de Santa Margarida (Castelo Branco, } \\
\text { Portugal). }\end{array}$ & HEp 17, 2008, 235 \\
\hline
\end{tabular}

Fig. 6. Testimonios de Bandi Vorteaeceo con sus distintas variantes fonéticas.

52 Diego Santos 1968, 97-98, no 6; Scheid 1998, 272-274, con n. 38.

53 Martins 2008, 46, fig. 5, no 11-12. 
Aproximadamente, $6 \mathrm{~km}$ hacia el sur de Seixo de Ansiăes, aparece otra inscripción que, de nuevo, podría mostrar un desplazamiento de individuos hacia la región. Se trata de la ofrenda votiva de Tiberius Claudius Sailcius, caballero de la III cohorte de lusitanos, dedicada a los dis deabusque Coniumbrig(ensium). ${ }^{54}$ El lugar se sitúa a unos $150 \mathrm{~km}$ en línea recta desde Conimbriga, por lo que la dedicación a los dioses y diosas de la ciudad sólo se podría entender en un contexto de migración. Teniendo en cuenta que el oferente es un soldado, las causas de la ofrenda podrían ser varias, pero el hecho de que en esta región existan minas y se observen otros posibles fenómenos de transferencia cultural, como el de Bandu Vordeaeco, nos induce a pensar en un nuevo proceso de emigración a territorios mineros.

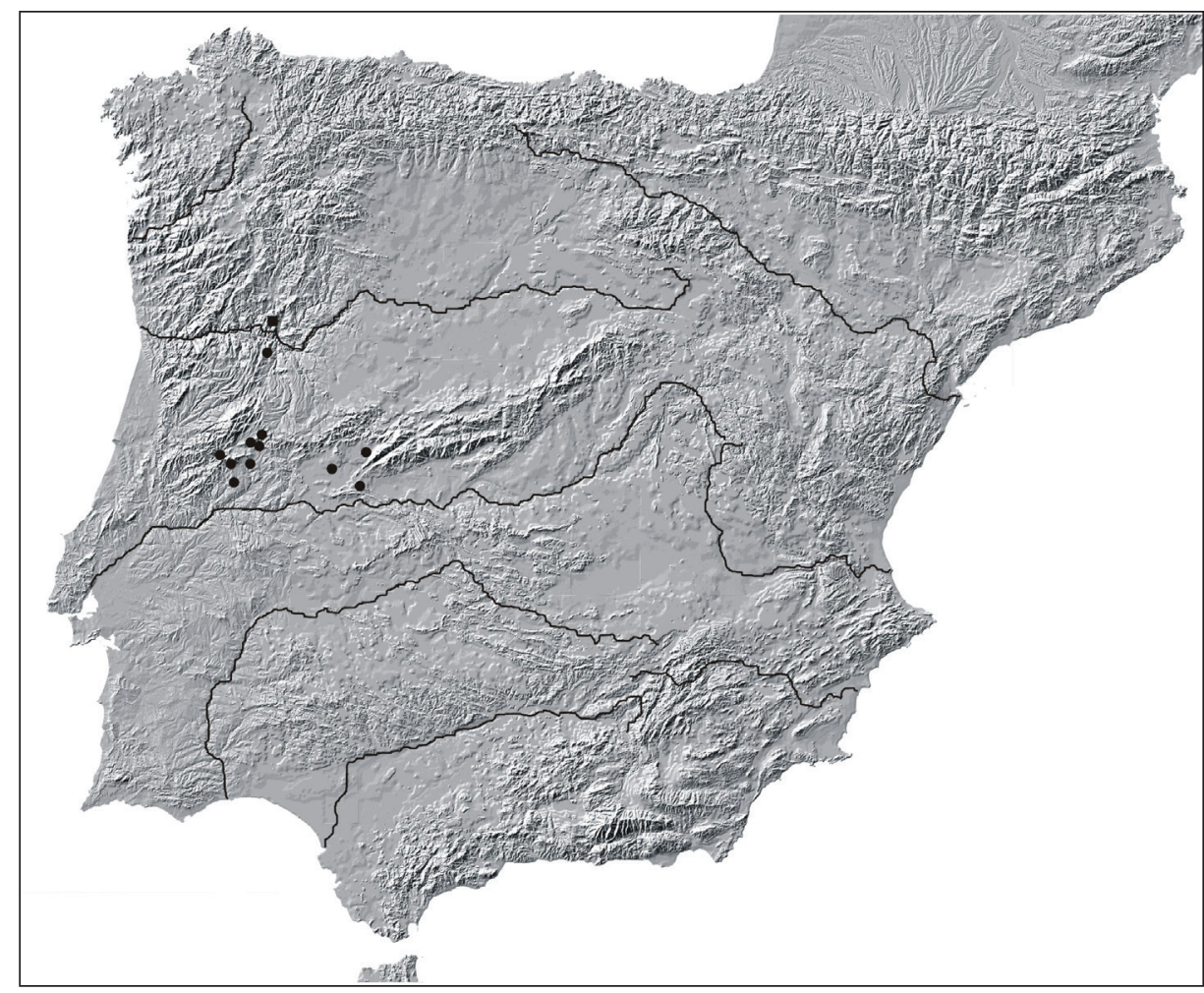

Fig. 7. Distribución territorial de las ofrendas a Bandi Vorteaeceo, con todas sus variantes fonéticas 


\section{Migraciones colectivas hacia las áreas urbanas y difusión religiosa}

Las ciudades hispanas fueron polos de atracción migratoria durante la Antigüedad, lo que supuso la llegada de determinados cultos que fueron mantenidos por la existencia de comunidades de inmigrantes. ${ }^{55}$

Sobre migraciones colectivas a las áreas urbanas, un probable caso es el de las aras votivas dedicadas al dios Lug o los Lugoves halladas en Lugo, que pudieron ser consecuencia de la difusión religiosa provocada por migraciones desde el territorio astur en el contexto de las guerras de los cántabros y astures contra Roma y de la coetánea fundación de la colonia Lucus Augusti. ${ }^{56}$

Un ejemplo de este tipo de transmisiones culturales de las zonas rurales a las ciudades se puede observar en la distribución de las dedicaciones votivas a Ataecina Turobrigensis. Esta diosa que, como muestra su apelativo, era adorada a nivel local en Turobriga, acabó teniendo un culto muy extendido por todo el sureste de Lusitania. Esto pudo ser consecuencia del desplazamiento de los habitantes de esta ciudad indígena cuando se entregaron las tierras a los colonos que se instalaron en Emerita Augusta, ya que la ciudad prerromana de Turobriga estaba en el territorio que ocupó la colonia. ${ }^{57} \mathrm{~A}$ tenor de la distribución de las ofrendas, se puede observar que algunos pobladores emigraron en grupo a determinadas áreas, puesto que se ven dedicaciones a Ataecina agrupadas en varias localidades concretas, donde debieron existir lugares de culto. Otros devotos de la deidad habrían emigrado a la capital de Lusitania donde, en algunos casos, vivieron como esclavos, como se plasma en varias inscripciones que pudieron instalarse en ámbitos privados. ${ }^{58}$

Sin embargo, otros testimonios que tradicionalmente se han considerado como ofrendas de emigrantes en áreas urbanas podrían no serlo. Es el caso de una ofrenda a las Matres hallada en la colina de "Los Cercos", de Medina de las Torres (Badajoz) que, según algunos autores, se dedicó a unas Matres Augustae por dos seviri augustales que probablemente ejercían su función sacerdotal en Contributa Iulia Ugultunia. ${ }^{59} \mathrm{La}$ inscripción está perdida y sólo consta una lectura de Barrientos que la interpretaba como una ofrenda a unas Maribus Augustis que Gimeno y Ramírez Sádaba

55 Este tipo de transmisiones cultuales se produjo en ciudades de todo el imperio. En Roma, por ejemplo, se constatan ofrendas votivas deidades del mundo céltico que se realizaron por grupos de inmigrantes, temporales o no, relacionados con actividades concretas. En este sentido, conocemos ofrendas a Epona y Camulus, hechas por soldados de caballería de la Galia (Noy 2000, 211-212), al caballero tracio y a otras deidades de la región hechas por tracios "to be read only by other Thracians" (Ibid., 222) y del ámbito oriental del imperio (Ibid., 232).

56 Olivares Pedreño 2010, 130-133. Las referencias en la mitología céltica de las Islas Británicas hacen referencia a una deidad de este tipo en masculino singular, mientras que las inscripciones hispanas aluden a la deidad como plural, los Lugoves y, en algún caso, aludiendo a deidades femeninas (MARCo SiMÓN 2006, 216).

57 Olivares Pedreño 2003, 306-308, con toda la argumentación sobre la difusión del culto a Ataecina a partir de la creación de la colonia romana y el consecuente desplazamiento de la población de Turobriga.

$58 \mathrm{Ibid}$., 309. Las ofrendas emeritenses a la diosa son CIL II 462; EE 9, 42, realizada por el esclavo Artemas y $E E$ 9, 43, efectuada por un individuo con tria nomina. Pero también acudieron adorantes de Ataecina a Metellinum, donde se testimonia una ofrenda realizada por un marido que no menciona su nombre, por lo que sería un testimonio privado (CIL II 605) y a Caesarobriga (URBINA 1993-1994, 29-41; ABASCAL 1995, 89).

59 Gimeno - Ramírez SÁdaba 1998, 160; Gómez-Pantoja 1999, 423, nº 9. 
consideraron como Matribus Augustis, suponiendo un nexo -tr- en el teónimo. Los autores consideraron la opción de que la lectura pudiera ser Laribus Augustis, pero la desecharon por otorgar credibilidad a Barrientos en su observación de la letra $m$ al principio del teónimo. ${ }^{60}$

En nuestra opinión, se ha de tener en cuenta que los oferentes eran dos seviri augustales que, de manera pública, hicieron la dedicación. Desde esta óptica, tenemos que considerar muy extraño que estos sacerdotes locales realizaran una ofrenda a deidades desconocidas por el conjunto de la población de Ugultunia y que, además, eran deidades no vinculadas a la estructura del estado romano ni al culto imperial. Además, hemos pensar que las Matres con el apelativo Augustae sólo aparecen en dos inscripciones de la Galia Narbonense, a pesar de que los testimonios de estas diosas con otros epítetos superan los trescientos en el continente. ${ }^{61}$ Por otra parte, las ofrendas a los Lares Augusti son muy numerosas. ${ }^{62}$ Además, es muy conocida la estrecha relación que se estableció desde época augustea entre los tradicionales $L a$ res Augusti y el culto imperial, patente en las numerosas ofrendas que hacían a estas deidades los magistri vici, en ocasiones los magistri primi, $y$ los seviri augustales. ${ }^{63}$ Por tanto, a pesar de que las consideraciones epigráficas podrían indicar una mayor probabilidad, como pensaban Gimeno y Ramírez Sádaba, de que fuera una ofrenda a las Matres, teniendo en cuenta la región, los dedicantes, seviri que hacen la ofrenda conjunta y el lugar, la ciudad de Ugultunia, hacen que sea más coherente considerar que estamos ante una dedicación a los Lares Augusti, por lo que el testimonio queda fuera de los objetivos de nuestro estudio.

\section{Migraciones individuales y testimonios privados de cultos indígenas}

Otras de las inscripciones dedicadas a deidades paleohispánicas que se erigieron lejos del ámbito de culto de las mismas aparecieron en entornos privados, donde sus propietarios las colocaron como ofrenda a sus dioses ancestrales. Un ejemplo podría ser el que procede de Porcuna (Jaén), que se trata de dos aras que aparecieron cuando se abrieron unos cimientos en una casa particular de la localidad. Tenían sendos foculi en su parte superior con huellas de haberse realizado fuego. El texto de una de ellas se interpretó del siguiente modo: Ara M(atribus) Veteribus, mientras que en la otra habían desaparecido todas las letras. ${ }^{64} \mathrm{La}$ carencia de contexto arqueológico y la actual desaparición de las piezas dificultan la significación de estas ofrendas pero si, como parece, en el texto conocido no consta el dedicante, cabe pensar en un ámbito

\footnotetext{
60 Gimeno - Ramírez SÁdaba 1998, 159-160.

$61 A E$ 1986, 477 (Bourg-Saint-Andeol) y CIL XII, 2672 (Alba-la-Romaine). Sobre las ofrendas a las Matres en el occidente europeo, vid. JuFER - LuGINBÜHL 2001, passim.

62 Hano 1986, 2337 ss.

63 Niebling 1956, 309-311 y 323 ( $A E$ 1964, 151 y 155; CIL VI, 445, 446, 447; PAscal 1964, 23; Gimeno - Ramírez SÁdABa 1998, 160, n. 16; Bert Lott 2004, 174 ss). Con respecto a los seviros augustales, $A E$ 1992, 302; $C I L \mathrm{II}^{2} / 7,938 ; A E$ 1989, 346a, 340a.

64 CeÁn Bermúdez 1832, 373; Cortés y López 1836, 237; CIL II 2128; González Román - Mangas 1991, 339-340, n 295; Gómez-Pantoja 1999 423, nº 10; NúÑez Marcén - Blanco 2002, 60, nº 18; CIL II²/7, 94 y 95.
} 
privado, cuyo propietario no consideraría necesario hacer constar su nombre. Ello es bastante habitual en numerosas inscripciones hispanas y, por el contrario, difícilmente comprensible si los altares estaban en un recinto público. ${ }^{65}$ Por tanto, debemos pensar que la erección de estos monumentos se realizó por un emigrante en su propiedad privada, por lo que no muestra una difusión cultural del culto a las Matres Veterae hacia la Bética ni una influencia del mismo en las comunidades del sureste hispano. De hecho, el culto a deidades que se podrían relacionar con las de Porcuna estaba muy localizado en un santuario existente en Abenden (Nideggen, Düren, Nord Rheinland-Westfalen) y el epíteto de las diosas tenía una clara variante fonética, puesto que estaba dedicado a las Matronae Veteranehae o Veteranae. ${ }^{66}$ Por otra parte, es cierto que el apelativo Veteribus acompaña en dos ocasiones a deidades femeninas plurales de Britannia, citadas como Deabus Vitiribus ${ }^{67}$ pero más frecuentemente a deidades masculinas plurales, puesto que once ofrendas se hicieron a unos dibus Veteribus $^{68} \mathrm{y}$, sobre todo, a una deidad masculina singular, aludida con diferentes variantes fonéticas que indicarían un origen no latino. ${ }^{69}$ Solo en un caso aparece esta deidad vinculada en Britannia a un teónimo concreto: es el caso de un Deo Mogont(i) Vitire San (cto). ${ }^{70}$ Por tanto, aunque es posible que el altar de Porcuna se dedicara a las Matres, existen demasiadas dificultades para que podamos considerar esa asociación como segura y, en cualquier caso, se trataría de una ofrenda instalada en un ámbito privado y con poca influencia sobre el resto de la comunidad.

La última inscripción que se ha atribuido a las Matres en la Bética sí es de lectura segura. Se dedicó a las Matres Aufaniae por un individuo de nombre Marcus Iulius Gratus. ${ }^{71}$ Es la única ofrenda a estas diosas con el apelativo Aufaniae, que es característico de Germania, puesto que conocemos cerca del centenar de inscripciones dedicadas a ellas centradas, principalmente, en Bonn, Mainz, Zulpich, Nettersheim y Köln. Es llamativo que, precisamente, un individuo llamado Quintus Bratonius Gratus, con el mismo cognomen que el dedicante de Carmo también aparece entre los oferentes a estas Aufaniae en Jülich (Aachen, Alemania). ${ }^{72}$ La ofrenda de Carmona se encontró en una fuente antigua junto a cinco bustos romanos y es de muy pequeño tamaño $(13 \times 15 \mathrm{~cm})$, lo que podría indicar que se encontraba en un ámbito doméstico. ${ }^{73}$ Esto sería lógico, teniendo en cuenta que estas Matres no eran conocidas en la

65 Olivares Pedreño 2013, passim.

66 SOMMER 1985, 313-352, especialmente 334 ss.

67 RIB 1047, RIB 1048; BIRLEY 2008, 35.

68 1) CIL VII 582; RIB 1456; 2) EE 1018; RIB 1457 3) CIL VII 502b; RIB 1549 (Huiteribus); 4) RIB 1605; 5) $C I L$ VII 728; RIB 1729; 6) CIL VII 729; RIB 1730; 7) EE 1057; RIB 1803; 8) EE 1956; RIB 1804; 9) $C I L$ VII 767; RIB 1805; ILS 4735; 10) $A E$ 1975, 566; 11) AE 2003, 1041. Sobre estos testimonios, véase también BiRLEY 2008, 39-43.

69 Se cita en diversas versiones casi medio centenar de inscripciones, como Deo Veteri, Vetri, Vheteri, Vitiri, Hueteri, Huitri, Huuetir o Vetiri (Webster 1986, 78-79; Green 2004, 237; BIrLey 2008, 35 y 39-44).

70 Birley 2008, 37.

71 Rada y Delgado 1885, 604-605; CIL II 5413; Fernández Chicarro 1968, 149-150; GonZÁlez 1983, 272.

72 Nesselhauf - Lieb 1959, 195; AE 1955, 36.

73 Stylow 2001, 99. 
Bética, por lo que cabe pensar en un culto privado llevado a cabo por un inmigrante de Germania, quizá un soldado. ${ }^{74}$

Otra inscripción que se puede incluir entre las de ámbito privado es la ofrenda a Bandua procedente de La Mezquitilla, a $3 \mathrm{~km}$ al suroeste de Sonseca (Toledo) entre variados vestigios de una villa rústica. ${ }^{75} \mathrm{La}$ inscripción estuvo mucho tiempo desaparecida sin que se pudiera comprobar su lectura y generando cierta confusión entre los investigadores, puesto que el territorio de culto de Bandua nunca llegó hasta tierras tan orientales de la Península Ibérica. ${ }^{76}$ Recientemente, tuvimos oportunidad de ver la pieza y es, en efecto, una ofrenda a Bandua Liviciesi, lo que podría hacernos pensar en una migración puntual o que el territorio fuera un ámbito minero, como algunos datos novedosos parecen indicar. ${ }^{77}$ Se trataría, por tanto, de emigrantes individuales que plasmarían en privado la veneración a la deidad ancestral de los lusitanos en tierras carpetanas.

En todo caso, aunque hemos presentado los intentos de las comunidades que se desplazaban hacia las minas y las capitales hispanas por mantener los signos de su identidad colectiva y por hacerlos patentes, lo cierto es que estos ámbitos, que permitían la visibilidad de esos emblemas culturales por la concentración de grupos con un origen común, a su vez llevaban implícito un conjunto de mecanismos que provocaban su progresiva transformación y su integración en la simbología, la concepción del mundo, la ritualidad y las costumbres de los romanos. La propia convivencia de poblaciones de muy distintos lugares, muchos de ellos altamente romanizados, encontraba su camino a una integración armónica por medio de la cultura romana, que era impulsada por todas las instituciones y agentes del estado imperial.

\section{Bibliografía}

Abascal, J. M.

(1995): "Las inscripciones latinas de Santa Lucía del Trampal (Alcuéscar, Cáceres) y el

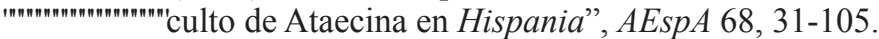

(1994): Los nombres personales en las inscripciones latinas de Hispania, Madrid-Murcia. ALFÖLDY, G.

(1987): "Epigraphica hispánica IX. Inschriften aus Ciudad Real", ZPE 67, 225-248.

(2001): "La sociedad del municipio de Carmo", [en] Caballos Rufino (ed.), 2001, 381-396.

Andreau, J. (1990): "Recherches récentes sur les mines romaines II", Revue Numismatique (6 $6^{\mathrm{a}}$ ser.) $32,85-108$.

74 CIL II 5413; Pflaum 1965, 241; Fernández Chicarro 1968, 150; GonZÁlez 1983, 272; NúÑEz MarcéN - Blanco 2002, 60-61. Según Alföldy (2001, 393), se trataría de lo contrario, de un carmonense que habría mostrado su agradecimiento a las Matres a su regreso desde Bonna en la Germania inferior, donde habría estado como soldado.

75 FiTA 1892, 146-147; EE 8, 179.

76 Olivares Pedreño 2002, 44 y 158.

77 Fita leía un dedicante en las últimas líneas ex / voto Ti/omace(s) pos(uit) (FiTA 1892, 146-147), Agradecemos encarecidamente a J. M. Abascal que nos permitiera el acceso a la inscripción y a la nueva interpretación de su lectura, antes de su próxima publicación. Sobre la ausencia de dedicante como indicativo de un entorno privado, vid. Olivares Pedreño 2013, passim. 
Arboledas, L. (2010): "La explotación masiva de los recursos mineros de Sierra Morena oriental: la minería iberorromana", [en] F. Contreras Cortés - J. Dueñas Molina (dirs.), La minería y la metalurgia en el Alto Guadalquivir: desde sus orígenes hasta nuestros días, Jaén, 123-201.

BeLl, P. (2002): “The fabric and structure of Australian mining settlements", [en] Knapp Pigott - Herbert (coords.), 2002, 27-38.

Bermejo Meléndez, J. (2011): Un modelo de implantación territorial y municipal en la Baeturia Celtica: Arucci/Turobriga, civitas et territorium, Tesis Doctoral leída el 19 de noviembre de 2010, Universidad de Huelva.

Bert LotT, J. (2004): The neighborhoods of augustan Rome, Cambridge.

Beyrie, A. - Fabre, J.-M. - Sablayrolles, R. (2000): "Les hommes de fer du dieu Ageio. Exploitation antique du fer dans les Hautes Baronnies (Hautes-Pyrénées)", Gallia 57, 37-52.

Birley, A. (2008): "Some Germanic deities and their worshippers in the British frontier zone", [en] H. Börm - N. Ehrhardt - J. Wiesehöfer (eds.), Monumentum et instrumentum inscriptum. Beschriftete Objekte aus Kaiserzeit und Spätantike als historische Zeugnisse. Festschrift für Peter Weiss zum 65. Geburtstag, Stuttgart, 31-46.

Blanco Freijeiro, A. (1962): “Antigüedades de Riotinto”, Zephyrus 13, 31-45.

BLÁZQUEZ, J. Ma

(1962): Religiones primitivas de Hispania I. Fuentes literarias y epigráficas, Madrid.

(1986): "La economía de la Hispania romana”, [en] R. Menéndez Pidal (dir.), Historia de España, Madrid, t. II, vol. I, 293-496.

Branigan, K. (1973): “Gauls in Gloucestershire?”, Transactions on the Bristol and Gloucestershire Archaeological Society 92, 82-95.

Caballos Rufino, A. (ED.), (2001): Carmona romana, Carmona.

CARBó, J. R. (2010): Los cultos orientales en la Dacia romana. Formas de difusión, integración y control social e ideológico (=Colección Vítor 265), Salamanca.

CEÁn Bermúdez, J. A. (1832): Sumario de las antigüedades romanas que hay en España, en especial las pertenecientes a las Bellas Artes, Madrid.

Ciobanu, R. (1999): “Les illyriens et la Dacie romaine”, Apulum 36, 199-214.

Ciugudean, H. (2012): “Ancient gold minning in Transylvania: The Roşia Montană-Bucium area", Caiete ARA 3, 101-178.

Clifford, J. (1997): Routes. Travel and translation in the late twentieth century, Cambridge, Mass.

Contreras Cortés, F. - Dueñas Molina, J. (2010): La minería y la metalurgia en el Alto Guadalquivir: desde sus orígenes hasta nuestros días, Jaén.

Corell, J. (2008): Inscripcions romanes del País Valencià IV (Edeta I el seu territori), Valencia.

Corell, J. - Gómez Font, X. (2002-2003): “Dues inscripcions de la provincia de Jaén”, Studia Philologica Valentina 6, 239-246.

CoRTÉs y LóPEz, M. (1836): Diccionario geográfico-histórico de la España Antigua tarraconense, bética y lusitana, con la correspondencia de sus regiones, ciudades, montes, ríos, caminos, puertos e islas en nuestros días, t. III, Madrid.

Davies, O. (1935): Roman mines in Europe, Oxford. 
Diego Santos, F.

(1968): "Ocho lápidas votivas de Astorga. Sobre epigrafía romana", Archivum. Revista de la Facultad de Filología 8, 91-106.

(1986): Inscripciones Romanas de la provincia de León, León.

Dobruna-Salihu, E. (2007-2008): "Some aspects of Illyrian life in Dacia”, Studia Antiqua et Archaeologica 13-14, 157-168.

Domergue, C. (1987): Catalogue des mines et fonderies antiques de la Péninsule Ibérique (=Publications de la Casa de Velázquez; Série archéologie 8), Madrid, 2 vols.

Domergue, C. (COORD.), (1989): Minería y metalurgia en las antiguas civilizaciones mediterráneas y europeas. Coloquio internacional asociado (Madrid, 24-28 octubre 1985), Madrid.

Dunbar Moodie, T. (1994): Going for gold: Men, Mines and Migration, London.

DUŠANIĆ, S.

(1977): “Aspects of Roman Mining in Noricum, Pannonia, Dalmatia and Moesia Superior”, $A N R W$ II.6, 52-94.

(1989): "The roman mines of Illyricum: organization and impact on provincial life", [en] Domergue (coord.), 1989, 148-156.

(2003): "Roman mining in Illyricum: historical aspects", [en] G. Urso (ed.), Dall'Adriatico al Danubio: L'Illirico nell'età greca e romana. Atti del convegno internazionale (Cividale del Friuli, 2003), (=I Convegni della Fondazione Niccolò Canusio 3), Pisa, 247-270.

Douglass, W. A. (2002): "The mining camp as a community", [en] Knapp - Pigott - Herbert (coords.), 2002, 97-108.

Euskirchen, M. (1993): “Epona”, BRGK 74, 607-838.

FAwCETt, L. (2000): Religion, Ethnicity and Social Change, New York.

Fernández ChicArro, C. (1968): “Altar der Matres Aufaniae aus Carmona (Spanien)”, Epigraphische Studien. Sammelband 5, 149-150.

FITA, F. (1901): "Epigrafía romana de Montánchez, Rena, Baños de la Encina, Linares, Santisteban del Puerto, Cartagena y Cádiz", BRAH 38, 450-473.

García, J. M. (1991): Religiões Antigas de Portugal - Aditamentos e Observações às Religiões da Lusitânia de J. Leite de Vasconcelos, Lisboa.

García CANClini, N. (1989): Culturas híbridas. Estrategias para entrar y salir de la modernidad, Méjico.

García Merino, C. (1975): Población y Poblamiento en Hispania romana. El conventus Cluniensis, Valladolid.

Gimeno Pascual, H. - Ramírez Sádaba, J. L. (1998): "Nuevos testimonios arqueológicos y epigráficos de Medina de las Torres (Badajoz), en un manuscrito inédito del siglo XIX", SPAL 7, 149-162 (http://dx.doi.org/10.12795/spal.1998.i7.09).

Gimeno Pascual, H. - Rothenhöfer, P. (2012): "Eine neue Weihung an die Rixamae in der Baeturia Celticorum und Martial IV 55", Veleia, 29, 435-439.

Gómez-Pantoja, J. (1999): “Las Madres de Clunia”, [en] F. Villar-F. Beltrán (eds.), Pueblos, lenguas y escrituras en la Hispania prerromana (=Acta Salmanticensia, Estudios Filológicos 273), Salamanca, 421-432.

González, C. - Mangas, J. (1991): Corpus de inscripciones latinas de Andalucía, vol. III, Jaén, tomo 1 Sevilla. 
GonzÁlez, J. (1983): "Divinidades prerromanas en Andalucía”, [en] M. Mayer - J. Gómez Pallarés (coords.), Religio deorum: actas del coloquio internacional de epigrafía "Culto y sociedad en Occidente”, Sabadell, 271-282.

GonzÁlez, J. (1989): Corpus de inscripciones latinas de Andalucía, vol. I, Huelva, tomo III Sevilla.

González CASASnovas, I. (2000): Las dudas de la Corona. La politica de repartimientos para la minería de Potosí (1680-1732), (=CSIC, Biblioteca de Historia de América 20), Madrid.

González Fernández, R. - Olivares Pedreño, J. C. (2010): “Una inscripción de época republicana dedicada a Salaecus en la región minera de Carthago Nova", AEspA 83, 109-126 (http://dx.doi.org/10.3989/aespa.083.010.006).

González Rodríguez, Ma C. - RAmírez, M. (2010): “Observaciones sobre la fórmula in hono. Argael. en un epígrafe de Cacabelos, León (CIL II 5672)”, [en] Serta Palaeohispanica in honorem Javier de Hoz (=Palaeohispanica 10), Zaragoza, 63-79.

Green, M. J. (2004): Guía completa del mundo celta, Madrid (1 $1^{\mathrm{a}}$ ed., London, 1992).

HaInZmann, M. - Schubert, P. (EDS.), (1986): Inscriptionum Lapidarium Latinarum Provinciae Norici usque ad annum MCMLXXXIV repertarum indices, Berlin.

Haley, E. W. (1986): Foreigners in roman imperial Spain: investigations of geographical mobility in the spanish provinces of the roman empire, 30 B.C.-A.D. 284, Ph. Diss., Columbia University, New York.

Hano, M. (1986): “A l’origine du culte impérial: les autels des Lares Augusti: Recherches sur les thèmes iconographiques et leur signification”, $A N R W$ 16.3, 2333-2381.

Harries, P. (1994): Work, Culture and Identity. Migrant Labourers in Mozambique and South Africa c. 1860-1910, Johannesburg.

Healy, J. F. (1978): Mining and Metallurgy in the Greek and Roman World, London.

Hirt, A. M. (2010): Imperial Mines and Quarries in the Roman World. Organizational Aspects $27 B C-A D 235$, Oxford.

Jenkins, R. (2008): Rethinking Ethnicity. Arguments and Explorations, London (2a ed.).

JufER, N. - LuginBüHL, T. (2001): Répertoire des dieux gaulois. Les noms des divinités celtiques connus par l'épigraphie, les textes antiques et la toponymie, Paris.

Knapp, J. B. - Pigott, V. C. - Herbert, E. (eds.), (2002): Social Approaches to an Industrial Past. The Archaeology and Anthropology of Mining, London.

LÓPez PAYer, M. G. - SoRia, M. - PeÑA, J. (1983): La minería hispano-romana en el término municipal de Baños de la Encina (Jaén), (=Serie Monográfica del Grupo de Estudios Prehistóricos de La Carolina 3), La Carolina.

Magallón, Ma Á. - Navarro, M. (1991): "Los desplazamientos humanos en el «conventus Caesaraugustanus» según la epigrafía”, Zephyrus 44, 405-421.

MañAnes, T. (1981): El Bierzo prerromano y romano (=Fuentes y estudios de historia leonesa 27), León.

MarchenA, J. (2000): “Alabanza de Corte y menosprecio de aldea. La ciudad y Cerro Rico de Potosí”, [en] J. Villa (ed.), Potosí. Plata para Europa, Sevilla, 15-71.

Marco Simón, F. (2006): "The cult of the Lugoves in Hispania", Acta Archaeologica Academiae Scientiarum Hungaricae 57, 209-218. 
Martins, C. M. Braz (2008): A exploração mineira romana e a metalurgia do ouro em Portugal (=Cadernos de Arqueologia. Monografias 14), Braga.

Mihailescu-BîRlibA, L. - CurCĂ, R-G. (2010): "Migration and acculturation in the Eastern european part of the roman world ( $1^{\text {st }}-7^{\text {th }}$ C. AD)", Studia Antiqua et Archaeologica 16, 189-196.

MoAtтi, C. (2006): "Translation, Migration, and Communication in the Roman Empire: Three Aspects of Movement in History", Classical Antiquity 25, 109-140 (http://dx.doi. org/10.1525/ca.2006.25.1.109).

Nemeti, S. (2004): "Bindus-Neptunus and Ianus Geminus at Alburnus Maior (Dacia)", Studia Historica. Historia Antigua 22, 91-101.

Nemeti, I. - Nemeti, S. (2010): "The barbarians within. Illyrian colonists in Roman Dacia", Studia Historica. Historia Antigua 28, 109-133.

Nesselhauf, H. - Lieb, H. (1959): “Dritter Nachtrag zu CIL XIII. Inschriften aus den germanischen Provinzen und dem Treverergebiet”, BRGK 40, 120-229.

Niebling, G. (1956): “Laribus Augustis magistri primi. Der Beginn des Compitalkultes der Lares und des Genius Augusti”, Historia 5, 303-331.

Noy, D. (2000): Foreigners at Rome. Citizens and Strangers, London.

NúÑEZ MARCÉN, J. - BlAnCO, A. (2002): “Una nueva propuesta de lectura y contextualización de la conocida ara votiva a las "Matribus Useis" de Laguardia (Álava)", Iberia 5, 49-64.

Olivares Pedreño, J. C.

(2000-2001): “Teónimos y fronteras étnicas: los lusitani”, Lucentum 19-20, 245-256.

(2001): “Teónimos y pueblos indígenas hispanos: los vettones", Iberia 4, 57-69.

(2002): Los dioses de la Hispania céltica (=Bibliotheca Archaeologica Hispana 15; Anejos de Lucentum 7), Madrid.

(2003): "Reflexiones sobre las ofrendas votivas a dioses indígenas en Hispania: ámbitos de culto y movimientos de población", Veleia 20, 297-313.

(2007): "Hipótesis sobre el culto al dios Cossue en El Bierzo (León): explotaciones mineras y migraciones", Palaeohispanica 7, 143-160.

(2010): "Los ástures del conventus Lucensis y el culto al dios Lug en el noroeste de Hispania", Dialogues d'Histoire Ancienne 36/2, 117-136 (http://dx.doi.org/10.3406/ dha.2010.3234).

(2013): "La omisión del dedicante en las inscripciones votivas de Hispania como indicio de su ubicación en ámbitos privados", Studia Historica. Historia Antigua 31, 59-87.

ORIA, M. (1997): “Testimonios religiosos en las minas de Riotinto: algunas reflexiones", SPAL 6, 205-220 (http://dx.doi.org/10.12795/spal.1997.i6.12).

PAscal, C. B. (1964): The Cults of Cisalpine Gaul (=Collection Latomus 75), Bruxelles.

Pérez Macías, J. A. - Vidal, Ma de la O. - Campos, J. M. (1997): “Arucci y Turobriga. El proceso de romanización de Los Llanos de Aroche”, CuPAUAM 24, 189-208.

Pflaum, H. (1965): "La part prise par les chevaliers romains originaires d'Espagne à l'administration imperial", [en] Les empereurs romains d'Espagne (Actes du Colloque international du CNRS, Madrid-Italica, 31 mars - 6 avril 1964), Paris, 87-121.

Pundt, H. A. (2012): Mining Culture in Roman Dacia: Empire, Community, and Identity at the Gold Mines of Alburnus Maior ca.107-270 C.E., Ph. Diss., Portland State University. 
Rabanal, M. A. - García Martínez, S. Ma (2001): Epigrafía romana de la provincia de León: revisión y actualización (=Historia y sociedad 8 ), León.

Rada y Delgado, J. D. (1885): Necrópolis de Carmona, Madrid.

SAntos Yanguas, N. (1997): "Los indígenas y la minería romana del oro en el suroccidente de Asturias", Memorias de Historia Antigua 18, 219-235.

Scheid, J. (1998): "La piété des procurateurs des Gaules et des Germanies", Cahiers du Centre Gustave Glotz 9, 265-275.

Sommer, M. (1985): "Das Heiligtum der Matronae Veteranehae bei Abenden", BJ 185, 313352.

Strobel, K. (2009): "The Galatians in the Roman Empire: historical tradition and ethnic identity in Hellenistic and Roman Asia Minor", [en] T. Derks - N. Roymans (eds.), Ethnic Constructs in Antiquity. The Role of Power and Tradition (=Archaeological Studies 13), Amsterdam, 117-144.

STYlow, A. U. (2001): "Una aproximación a la Carmo romana a través de su epigrafía”, [en] Caballos Rufino (ed.), 2001, 95-106.

TANDeter, E. (1992): Coacción y Mercado. La minería de la plata en el Potosí colonial, 16921826, Madrid.

Timberlake, S. (2004): "Early leats and hushing remains suggestions and disputes on roman mining and prospection for lead", Mining History: the Bulletin of the Peak District Mines Historical Society 15, n 4/5, 64-76.

Tranoy, A. (1981): La Galice romaine. Recherches sur le nord-ouest de la Péninsule Iberique dans l'antiquité, Paris.

UrbinA, D. (1993-1994): “Ataecina y Urilouco. Dos divinidades indígenas en Talavera de la Reina”, Minius 2-3, 29-51.

Webster, G. (1986): The British Celts and their Gods under Rome, London.

WOLLMANN, V.

(1989): "Nouvelles données concernant la structure socio-ethnique de la zona minière de la Dacia Superior", [en] Domergue (coord.), 1989, 107-118.

(1996): Mineritul metalifer, extragerea săeii şi carierele de piatră în Dacia Romană - Der Erzbergbau, die Salzgewinnung und die Steinbrüche im Römischen Dakien, Cluj-NapocaKlausenburg. 